\title{
Quais variáveis ambientais melhor explicam a diferenciação estrutural e florística de cerrado stricto sensu e floresta estacional semidecidual?
}

\author{
Gabriel Venâncio Pereira Mariano ${ }^{1 *}$ Jovan Martins Rios $^{1}$ Gabriela Teodoro Rocha ${ }^{1}$ Vanuza Garcia \\ Silva ${ }^{1}$ Lilian Cristina Silva Santos ${ }^{1}$ Valdivino Domingos Oliveira Junior ${ }^{1}$ Vagner Santiago Vale ${ }^{1}$
}

${ }^{1}$ Universidade Estadual de Góias, Rodovia GO - 330, KM 241 - Anel Viário, S/N, CEP: 75780-000, Goiás, MS,Brasil

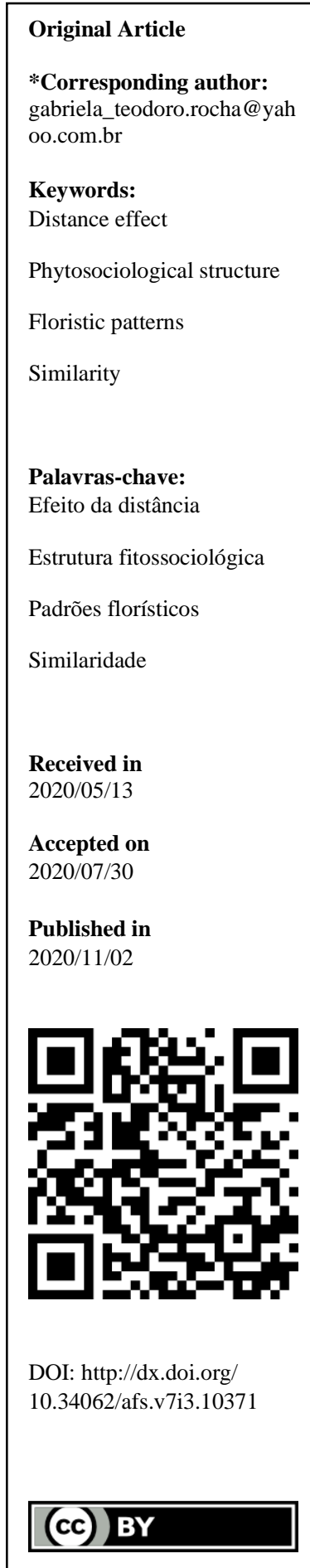

RESUMO: As formações de cerrado e florestais são determinadas por uma gama de variáveis abióticas, sendo importante a realização de estudos capazes de delimitar quais fatores condicionam essas formações. $\mathrm{O}$ objetivo deste trabalho foi definir fatores abióticos que melhor explicaram a diferenciação estrutural e florística entre as fitofisionomias de cerrado stricto sensu e floresta estacional semidecidual. Foram utilizados dados de densidade por hectare para espécies amostradas em 33 áreas localizadas no domínio do Cerrado e utilizados técnicas multivariadas para verificar padrões para estas duas fitofisionomias. As variáveis ambientais determinantes para a diferenciação das comunidades foram latitude, altitude, temperatura média anual e a distância do oceano. Foi possível delimitar três grupos em relação à composição de espécies, florestas estacionais de interior, florestas estacionais costeiras e cerrados. Em termos florísticos, as florestas localizadas no interior do país têm maior similaridade entre si em relação à similaridade entre as florestas mais próximas à costa. $\mathrm{O}$ mesmo ocorre para os cerrados, possuidores de alta similaridade entre as comunidades estudadas. As florestas mais costeiras apresentam forte variação florística e mesmo comunidades próximas podem ser muito divergentes em termos florísticos, logo a riqueza estimada dessas áreas é maior em relação a quaisquer comunidades de interior analisadas. Para as comunidades localizadas no interior do país, cerrados e florestas semideciduais, a distância entre as áreas parece ter um papel mais determinante sobre a composição florística.

\section{Which environmental variables better explain the structure and floristic of cerrado stricto sensu and the semi deciduous seasonal forest?}

ABSTRCT: Cerrado and forest formations are determined by a range of abiotic variables, and we need studies to determine which factors influence these formations. The objective of this study was to define the variables which best explain the structural and floristic differentiation between distinct cerrado stricto sensu and seasonal semideciduous forest. Species density per hectare data were catalogated in 33 inventories in Cerrado domain and multivariate analyses were used to verify patterns between cerrado stricto sensu and semidecidual seasonal forest. The main determinant environmental variables were latitude, altitude, annual average temperature and distance from the ocean. It was possible to delimit three groups, inland cerrados, inland semideciduous forests and coastal seasonal forests. In floristic terms, the forests located in the interior of the country have greater similarity to each other, comparing with the forests closest to the coast. The same happens for the cerrado stricto sensu, which have high similarity between the studied communities. Most coastal forests present strong floristic variation among the analyzed communities, and even near communities can be very divergent. For the communities (cerrado and seasonal forests located in the interior of the country, the distance between the areas seems to play a more decisive role on the floristic composition and structure of these areas. 
Introdução

O conhecimento da composição florística e estrutura das fitofisionomias possuem implicações diretas nas ações de conservação das formações vegetais do Brasil (Chaves et al. 2013). No entanto, a maioria dos estudos focam nas variações florísticas (ocorrência de espécies comuns) entre diferentes comunidades (Farias et al. 2012), sendo raros os estudos que demonstram quais variáveis ambientais são as principais responsáveis pela distribuição das espécies, sobretudo utilizando dados de dominância absoluta das espécies em cada área amostrada. As variáveis ambientais possuem um papel de influência na composição e estrutura de comunidades vegetais e podem ser essenciais para a estimativa da biomassa, da biodiversidade (Roquette 2018), e o estado nutricional da vegetação destas áreas.

Comparações entre florestas existentes no domínio dos Cerrados e da Mata Atlântica demonstram que as formações florestais interioranas no Brasil possuem alta similaridade florística com formações florestais úmidas da costa brasileira (IBGE 2012). Existe, uma conhecida divisão entre florestas de interior, chamadas de florestas estacionais semideciduais, daquelas próximas a costa, chamadas de florestas atlânticas úmidas. Esse tipo de vegetação é encontrada ao longo dos Cerrados, porém, geralmente constituem fragmentos próximos a recursos hídricos (Pereira et al. 2011).

São necessários estudos comparativos para determinar quais fatores abióticos explicam as diferenças entre estas florestas estacionais semideciduais e os cerrados stricto sensu, formação dominante do domínio Cerrado. Estas fitofisionomias são bastante diferentes na paisagem e tendem a possuir diferenciações em sua estrutura. Parâmetros como riqueza de espécies, densidade de árvores, área basal ocupada pelas árvores, diversidade de espécies e equitabilidade são frequentemente utilizados para descrever diferentes comunidades (Rodrigues-Souza et al. 2015; Vale et al. 2017) e podem ser considerados variáveis bióticas úteis na determinação de padrões entre as fitofisionomias.

Tais fatores devem influenciar de forma conjunta na distribuição de espécies arbóreas e a formação de diferentes comunidades florísticas (Scipioni et al. 2012). A heterogeneidade entre as áreas pode afetar a distribuição das espécies e, por consequência, a diversidade beta, que pode ser expressa por índices de similaridade. Estes índices podem ser calculados com dados de ocorrência de espécies em comum nas áreas e, são os mais utilizados por pesquisadores na busca de padrões florísticos, por serem mais fáceis e práticos. No entanto, dados de ocorrência ignoram a densidade de indivíduos de cada espécie nas áreas analisadas, o que pode dificultar comparações e prejudicar a compreensão de padrões estruturais.

Um exemplo é a forte variação estrutural que duas comunidades próximas podem apresentar, mesmo tendo uma variação florística baixa, ao mesmo tempo que comunidades distantes podem apresentar aspectos estruturais semelhantes e flora distinta. Neste contexto, a distância horizontal e vertical entre as comunidades pode ser um importante causador de dissimilaridade florística, atuando de maneira diferente para cada fitofisionomia.

Um maior conhecimento sobre os padrões florísticos e estruturais destas fitofisionomias e o entendimento do efeito de variáveis ambientais sobre estes padrões podem auxiliar estratégias de restauração e preservação das áreas presentes no domínio do Cerrado. Estes estudos fornecem informações a respeito das comunidades arbóreas e suas relações com condições ambientais regionais (Higuchi et al. 2012).

Diante do exposto, o objetivo deste trabalho foi definir quais são os principais fatores ambientais que melhor explicaram a diferenciação estrutural e florística entre as fitofisionomias de cerrado stricto sensu e floresta estacional semidecidual.

No estudo espera-se que temperatura, altitude e pluviosidade sejam determinantes na explicação da diferenciação estrutural entre estas fitofisionomias e que a distância entre as áreas tenha um papel significativo em relação às diferenças florísticas.

Buscou-se responder às seguintes questões: As variáveis ambientais influenciam na determinação destas fitofisionomias? É possível identificar quais são estas variáveis? Quais variáveis melhores explicam as modificações florísticas existentes entre estas fitofisionomias? Qual é o papel da distância na determinação das semelhanças e diferenças entre as comunidades?

\section{Material e Métodos}

O banco de dados utilizado no presente estudo foi obtido por meio de revisão de literatura. As áreas dos estudos que avaliaram a estrutura fitossociológica de áreas de cerrado stricto sensu e florestas estacionais semideciduais utilizados estão situadas nos estados de Minas Gerais, São Paulo, Mato Grosso, Mato Grosso do Sul e Goiás (Figura 1). 


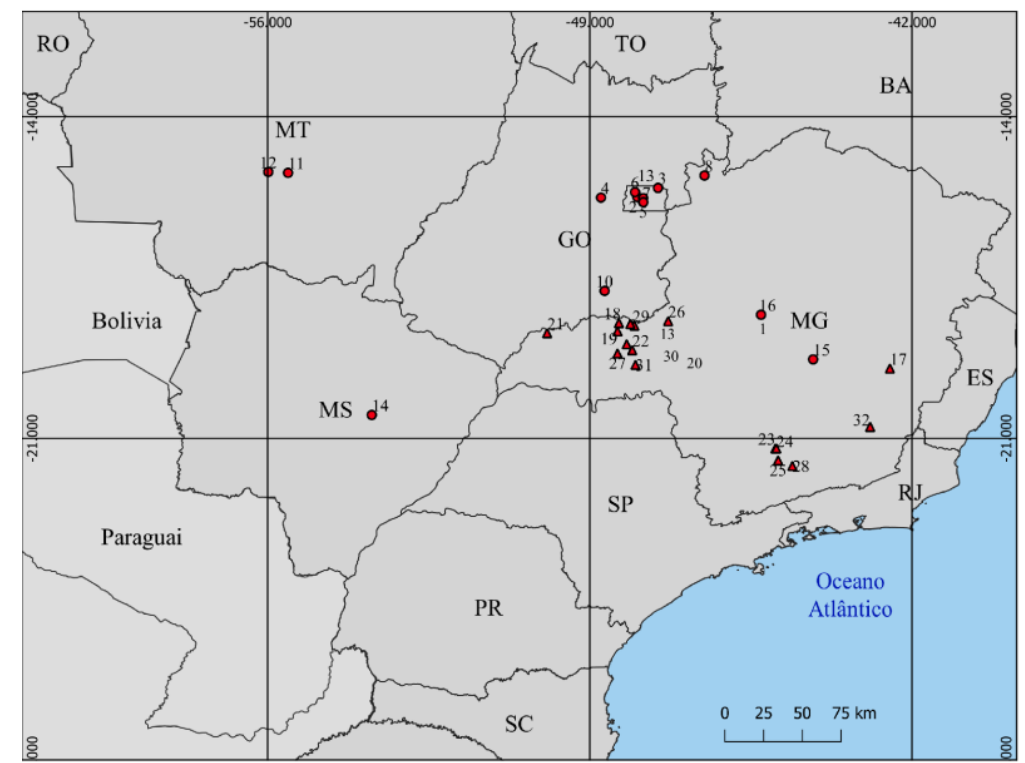

Figura 1. Localização Geográfica das áreas de estudos. Quadrados = áreas de cerrado; círculo = áreas de floresta.

O diâmetro mínimo de inclusão utilizado foi de $4,8 \mathrm{~cm}(\mathrm{CAP} \geq 15 \mathrm{~cm})$. e as análises foram realizadas por unidade de área (ha).

Similaridades - Foram elaborados dendrogramas de similaridade utilizando dados de ocorrência de espécies em comum entre as áreas., por meio do coeficiente de similaridade genética de Sørensen-Dice (Dice, 1945). Para dados de densidade foi utilizado o coeficiente de distância de Bray-Curtis (Krebs, 1989), verificando a similaridade entre as diferentes matrizes utilizadas. Os resultados dos índices variam de 0 a 1 , sendo que uma similaridade próxima a 1 é considerada alta e próxima a 0, é considerada baixa (Horn, 1966). As análises foram realizadas no software PAleontological STatistics - PAST (Hammer 2001).

Variáveis ambientais - Os dados ambientais de temperatura e precipitação de cada área foram obtidos dos próprios estudos, na de estações meteorológicas mais próximasou pelos dados de Peel et al. (2007), nessa ordem de preferência. Estas informações foram separadas em "período seco" de abril a setembro e "período chuvoso" de outubro a março. As distâncias horizontais (distância mais próxima da área em linha reta paralela a linha do Equador) e vertical (distância mais próxima do oceano em linha reta perpendicular à linha do Equador) do oceano atlântico, assim como altitude foram obtidas no Google Earth Pro (Versão 7.3.2.5776).

Para a avaliação das correlações entre a distribuição das espécies arbóreas e as variáveis ambientais (pluviosidade total, pluviosidade do período chuvoso, pluviosidade do período seco, relação pluviosidade do período seco/período chuvoso, distância média do oceano, distância vertical do oceano, distância horizontal do oceano, temperatura no período seco, temperatura no período chuvoso, temperatura média, altitude, latitude e longitude), foi realizada uma análise de correspondência canônica (CCA) (Braak, 1987) associada ao teste de Monte Carlo para avaliar o nível de significância dos eixos de ordenação, utilizando-se o software PC-ORD versão 6.0 (McCune e Mefford 2011).

Espécies indicadoras dos grupos formados - De forma complementar, baseado nos grupos formados pelos dendrogramas e CCA, para definir as espécies indicadoras dos grupos florísticos, utilizouse também a divisão hierárquica dicotômica por TWINSPAN (two-way indicator species analysis; Hill, 1979) com nível de corte de 0, 2, 5 e 10.

Riqueza florística dos grupos formados - A partir dos grupos florísticos formados pelas análises anteriores, foram estimados a riqueza de cada grupo florístico, calculada pelo estimador de riqueza Bootstrap por meio do software EstimateS version 7.5 (Colwell 2005). Este estimador considera os dados obtidos de todas as espécies, não acrescentando valores às espécies raras Colwell e Coddington (1994). Foram realizadas curvas de rarefação utilizando-se os resultados dos estimadores para cada grupo florístico.

Efeito da distância - Foram realizadas análises de regressões utilizando as similaridades florísticas entre as áreas (Sørensen-Dice) e as similaridades florístico-estruturais (1-Bray-Curtis, uma vez que o coeficiente de Bray-Curtis é um coeficiente de dissimilaridade, sendo necessário a operação 1-Valor do coeficiente para torná-lo um coeficiente de similaridade) com a distância entre as áreas de cada grupo florístico formado.

\section{Resultados e discussões}

Similaridades - A matriz inicial possuiu 35492 árvores pertencentes a 674 espécies, 298 gêneros e 84 famílias em 33 áreas, sem retirar as áreas que não estão classificadas como cerrado 
stricto sensu. O dendrograma de similaridade baseado no coeficiente de Sørensen-Dice (ocorrência) evidenciou a formação de dois grupos

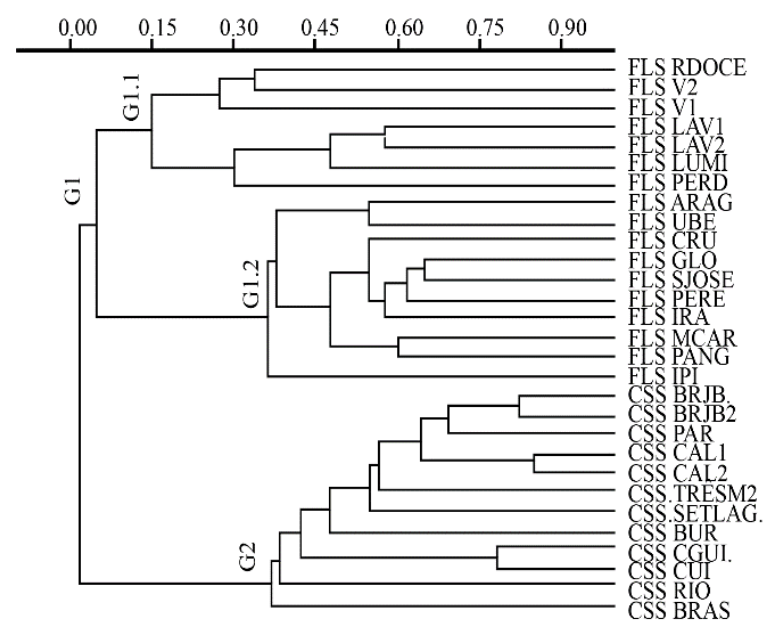

distintos com similaridade próxima a 0,50 (Figura 2A).

B.

Bray-Curtis

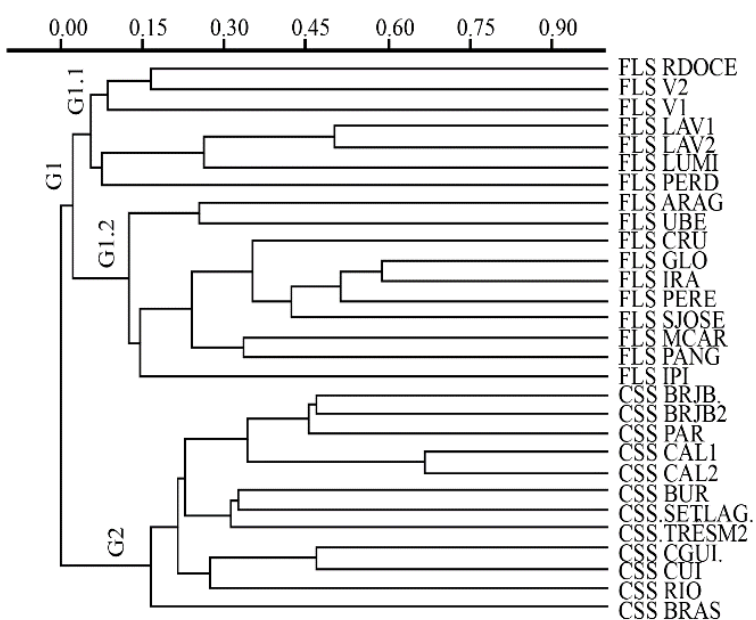

Figura 2. Análise de Agrupamento (A = Sørensen-Dice e $B=$ Bray-Curtis) para 29 áreas com base no nível taxonômico de espécies. Legenda: G2: CSS BRAS Cerrado stricto sensu Brasília; CSS BRJB = Cerrado stricto sensu Brasília JB; CSS BRJB2 = Cerrado stricto sensu Brasília JB2; CSS BUR = Cerrado stricto sensu Buritis; CSS CA1 = Cerrado stricto sensu Caldas Novas 1; CSS CA2 = Cerrado stricto sensu Caldas Novas 2; CSS CGUI = Cerrado stricto sensu Chapada dos Guimarães; CSS CUI = Cerrado stricto sensu Cuiabá; CSS PAR = Cerrado stricto sensu Paraná; CSS RIO = Cerrado stricto sensu Ribas do Rio; CSS SLAG = Cerrado stricto sensu Sete Lagoas; CSS TM2 = Cerrado stricto sensu Três Marias; G1: G1.1: FLS RDOCE = Floresta semidecidual Rio Doce; FLSLAV1 = Floresta semidecidual Lavras1; FLSLAV2 = Floresta semidecidual Lavras 2; FLS VI1 = Floresta semidecidual Viçosa 1 e FLS VI2 = Floresta semidecidual Viçosa 2; FLS LUMI = Floresta semidecidual Luminárias; FLS PERD = Floresta semidecidual Perdizes; G1: G1.2: FLSAFARA = Floresta semidecidual Água Fria Araguari; FLSCRU = Floresta Semidecidual Cruzeiro; FLSGLO = Floresta semidecidual Glória; FLSIPI = Floresta semidecidual Ipiaçu; FLSIRA = Floresta semidecidual Irara; FLSMCAR = Floresta semidecidual Monte Carmelo; FLSPANG = Floresta semidecidual Panga; FLSPERE = Floresta semidecidual Pereiras; FLSSJOSE = Floresta semidecidual São José; FLSUBE = Floresta semidecidual Uberaba.

O primeiro grupo foi formado pela fitofisionomia cerrado stricto sensu(G1.1), e o segundo grupo por florestas semideciduais(G1.2). Porém, este último apresentou a formação de dois subgrupos caracterizados por florestas localizadas distantes da costa (aqui chamadas de florestas de interior) e florestas estacionais mais próximas à costa brasileira (aqui chamadas de florestas costeiras).

O primeiro grupo de florestas pode ser dividido em dois subgrupos, em que o primeiro subgrupo mostrou um nível de similaridade de cerca de $37 \%$, sendo constituído pelas áreas localizadas mais próximo à costa brasileira (FLSPERD, FLSLUMI, FLSLAV1, FLSLAV2, FLSVI1, FLSVI2 e FLSRDOCE). As 10 espécies mais abundantes deste grupo foram Gymnanthes concolor (Spreng.) Müll. Arg, Euterpe edulis Mart., Galipea jasminiflora (A. St.-Hil.) Engl., Bixa arborea Huber, Myrsine umbellata Mart., Guatteria schomburgkiana Mart., Psychotria sessilis (Vell.) Müll. Arg., Lacistema pubescens Mart., Esenbeckia grandiflora Mart., Aparisthmium cordatum (A. Juss.) Baill.. O segundo subgrupo mostrou nível de similaridade de $15 \%$, constituído por florestas localizadas distantes da costa: FLSPANG, FLSMCAR, FLSIRA, FLSPERE, FLSSJOSE, FLSGLO, FLSCRU, FLSUBE, FLSARAG. As 10 espécies mais densas deste subgrupo foram: Cheiloclinium cognatum (Miers) A.C. Sm., Siparuna guianensis Aubl., Cordiera sessilis (Vell.) Kuntze, Aspidosperma discolor A. DC., Protium heptaphyllum (Aubl.) Marchand, Astronium nelsonrosae Santin., Duguetia lanceolata A. St.-Hil., Casearia grandiflora Cambess., Cryptocarya aschersoniana Mez e Terminalia glabrescens Mart.

As áreas de cerrados apresentaram um nível de similaridade de cerca de $32 \%$, sendo formadas pelas áreas de cerrado: CSSRRIO, CSSBR, CSSCCUI, CSSCGUI, CSSBU, CSSTM, CSSTM2, CSSLAG, CSSCA2, CSSCA1, CSSPAR, CSSBRJB2, CSSBRJB, CSSBRAS. As 10 espécies mais densas do grupo foram Tabebuia aurea (Silva Manso) Benth. \& Hook. f. ex S. Moore, Qualea 
parviflora Mart., Qualea grandiflora Mart., Ouratea hexasperma (A. St.-Hil.) Baill., Kielmeyera coriacea Mart. \& Zucc., Stryphnodendron adstringens (Mart.) Coville, Magonia pubescens A. St.-Hil., Byrsonima coccolobifolia Kunth, Styrax ferrugineus Nees \& Mart. e Pouteria ramiflora (Mart.) Radlk..

De acordo com a análise de grupo, observouse que, floristicamente, as comunidades do interior apresentaram maior semelhança entre si, porém as comunidades presentes na costa litorânea apresentaram florísticas distintas em relação àquelas localizadas no interior. $\mathrm{O}$ agrupamento de densidade (Figura 2B) dos indivíduos formou grupos menos precisos, porém é possível notar semelhanças entre os grupos formados em relação à análise de similaridade de ocorrência.

Assim, a separação dos grupos no dendrograma de similaridade baseado na ocorrência das espécies apresentou valores superiores ao dendrograma baseado na densidade das espécies. Mesmo que a flora arbórea seja bastante semelhante, as espécies dominantes podem não ser, indicando distinção estrutural entre as áreas. Muitas espécies com ampla distribuição e comumente amostradas aumentam o valor da similaridade entre as áreas. Foi o caso de espécies como Cabralea canjerana (Vell.) Mart., Chrysophyllum gonocarpum (Mart. \& Eichler ex Miq.) Engl., Copaifera langsdorffii Desf., Eriotheca candolleana (K. Schum.) A. Robyns, Hymenaea courbaril L., Lonchocarpus cultratus (Vell.) A.M.G. Azevedo \& H.C. Lima $e$ Luehea grandiflora Mart. que ocorreram em 10 ou mais florestas. Destas apenas Luehea grandiflora e Copaifera langsdorffii estão entre as 30 espécies florestais mais densas das florestas utilizadas neste estudo, demonstrando que a alta similaridade florística pode não condizer com a estrutura entre cada fragmento. Além disso, a densidade de Cabralea canjerana,e Lonchocarpus cultratus foi muito superior nas florestas mais próximas à região costeira, enquanto Luehea grandiflora, Copaifera langsdorffii e Hymenaea courbaril foram mais densas nas florestas mais interioranas. Existe um conjunto de espécies que ocorre com frequência, porém em baixa densidade nas florestas estacionais (Lopes et al. 2011c) o que aumenta a similaridade por presença/ausência mesmo para áreas distantes geograficamente.

No grupo de cerrado, 15 espécies ocorreram em 10 ou mais áreas, mas a densidade entre cada uma destas espécies foi bastante distinta entre as áreas, o que reduziu a similaridade em comparação com àquela verificada na análise por presença/ausência. As espécies mais presentes nas áreas, e também com alta densidade, foram Qualea grandiflora, Qualea parviflora, Kielmeyera coriacea e Stryphnodendron adstringens. Dentre as mais encontradas, Qualea grandiflora, Qualea parviflora e Kielmeyera coriacea são espécies típicas e indicadoras de ambiente de cerrado (Lopes et al. 2011a; Kratka e
Ataídes 2014). As três primeiras estão entre as sete espécies mais comuns encontradas para cerrados do Brasil Central (Lima et al. 2014).

Apesar de não haver separação entre as áreas de cerrado, as áreas com alto grau de antropização, uma próxima a zona urbana de Brasília (CSS BRAS) e três cerrados localizados em Mato Grosso e Mato Grosso do Sul (CSS CGUI, CSS CUI, CSS RDOCE) apresentaram as menores similaridades com as demais áreas na análise florística (Sørensen) e, formaram pequenos subgrupos na análise florísticoestrutural que considerou a densidade dos indivíduos (Figura 2).

Variáveis ambientais - Para a matriz de variáveis ambientais, foram eliminadas as variáveis que possuíam baixa correlação com os eixos (pluviosidade total, pluviosidade do período chuvoso, relação pluviosidade do período seco/período chuvoso, pluviosidade do período seco e distância média do oceano), cujo valor de correlação foi inferior a 0,4 para os dois eixos. Também foram eliminadas as variáveis altamente correlacionadas positivamente com outras variáveis, como a longitude e distância vertical do oceano foram retiradas por serem altamente correlacionadas com a distância horizontal do oceano; a temperatura no período seco e no período chuvoso, que foram retiradas por serem altamente correlacionadas com temperatura média; a pluviosidades no período seco, chuvoso e médias, que foram retiradas por serem altamente correlacionadas com a altitude. As variáveis bióticas analisadas apresentaram alta variabilidade (espécies, densidade (n/ha), área basal $\left(\mathrm{m}^{2} / \mathrm{ha}\right)$, Shannon e equitabilidade), pouco contribuíram para a CCA e foram retiradas desta análise (dados apresentados em material suplementar). Restaram quatro variáveis na CCA final, sendo todas abióticas (altitude (m), temperatura média, distância horizontal do oceano e latitude) (Tabela 1).

Os autovalores da análise de correspondência canônica (CCA) dos dois eixos de ordenação foram 0,757 e 0,585 , respectivamente. Valores acima de 0,3 para CCA são considerados altos (Felfili et al. 2011), indicando a existência de grupos bem definidos. Os valores de correlação para espécieambiente também foram altos, 0,95 para o eixo $1 \mathrm{e}$ 0,944 para o eixo 2 . Os dois eixos explicaram apenas $77,87 \%$ da variância dos dados (eixo $1=43,92 \%$ e eixo $2=33,95 \%$ ). O resultado do teste de Monte Carlo indicou, para ambos os eixos, que as espécies estão altamente correlacionadas com as variáveis ambientais $(\mathrm{p}<0,05)$.

Os autovalores da análise de correspondência canônica (CCA) dos dois eixos de ordenação foram 0,757 e 0,585 , respectivamente. Valores acima de 0,3 para CCA são considerados altos (Felfili et al. 2011), indicando a existência de grupos bem definidos. Os valores de correlação para espécieambiente também foram altos, 0,95 para o eixo $1 \mathrm{e}$ 
0,944 para o eixo 2 . Os dois eixos explicaram apenas $77,87 \%$ da variância dos dados (eixo $1=43,92 \%$ e eixo $2=33,95 \%)$. O resultado do teste de Monte
Carlo indicou, para ambos os eixos, que as espécies estão altamente correlacionadas com as variáveis ambientais $(\mathrm{p}<0,05)$.

Tabela 1. Áreas de cerrado e florestas estacionais amostradas com semelhante metodologia e critério de inclusão utilizadas nas análises multivariadas. $\mathrm{N}=$ número da área; Lat. = latitude (decimais), Alt. = altitude $(\mathrm{m}), \mathrm{Sp} .=$ número de espécies, TM = temperatura média $\left({ }^{\circ} \mathrm{C}\right)$, DH.Oc $=$ Distância horizontal do oceano $(\mathrm{km})$.

\begin{tabular}{|c|c|c|c|c|c|c|c|}
\hline $\mathrm{N}$ & Município & Legenda & Lat. & Alt. & TM & DH.Oc & Autores \\
\hline 1 & Brasília & CSS BRAS & 15.86 & 1056 & 21.0 & 974.1 & Assunção e Felfili 2004 \\
\hline 2 & Brasília & CSS BRJB. & 15.64 & 838 & 21.0 & 974.1 & Fonseca e Silva-Junior 2004 \\
\hline 3 & Brasília & CSS BRJB2 & 15.52 & 1056 & 21.0 & 956.1 & Fonseca e Silva-Junior 2004 \\
\hline 4 & Buritis & CSS BUR & 15.28 & 709 & 22.0 & 982.1 & Nettesheim et al. 2010 \\
\hline 5 & Caldas Novas 1 & CSS CAL1 & 17.79 & 930 & 22.1 & 948.1 & Lopes et al. 2009 \\
\hline 6 & Caldas Novas 2 & CSS CAL 2 & 17.79 & 930 & 22.1 & 956.1 & Lopes et al. 2009 \\
\hline 7 & $\begin{array}{l}\text { Chapada dos } \\
\text { Guimarães }\end{array}$ & CSS CGUI. & 15.22 & 437 & 24.6 & 1786.4 & Oestreich et al. 2014 \\
\hline 8 & Cuiabá & CSS CUI & 15.2 & 310 & 25.3 & 1402.0 & Oestreich et al. 2014 \\
\hline 9 & Paraopeba & CSS PAR & 15.77 & 1000 & 21.0 & 982.1 & Balduino et al. 2005 \\
\hline 10 & Ribas do Rio & CSS RIO & 20.49 & 438 & 22.6 & 1025.7 & Carielo et al. 2012 \\
\hline 11 & Sete Lagoas & CSS.SETLAG. & 19.28 & 732 & 20.0 & 798.6 & Pereira et al. 2013 \\
\hline 12 & Três Marias & CSS.TRÊSM2 & 18.31 & 570 & 21.1 & 605.7 & Giácomo et al. 2013 \\
\hline 13 & Rio Doce & FLS RDOCE & 19.48 & 372.5 & 21.1 & 329.3 & Lopes et al. 2002 \\
\hline 14 & Araguari & FLS ARAG & 18.49 & 680 & 21.4 & 122.7 & Vale et al. 2009 \\
\hline 15 & $\begin{array}{l}\text { Distrito de } \\
\text { Cruzeiro dos } \\
\text { Peixotos }\end{array}$ & FLS CRU & 18.67 & 565 & 21.4 & 883.4 & Kilca et al. 2009 \\
\hline 16 & Uberlândia & FLS GLO & 18.95 & 880 & 20.9 & 839.8 & Lopes et al. 2011b \\
\hline 17 & Ipiaçu & FLS IPI & 18.71 & 442 & 23.2 & 1004.6 & Gusson et al. 2009 \\
\hline 18 & Uberlândia & FLS IRA & 19.08 & 915 & 20.9 & 909.9 & Prado Júnior et al. 2010 \\
\hline 19 & Lavras & FLS LAV1 & 21.13 & 925 & 18.7 & 822.6 & Espirito-Santo et al. 2002 \\
\hline 20 & Lavras & FLS LAV2 & 21.13 & 884 & 18.7 & 217.4 & $\begin{array}{l}\text { Machado e Oliveira- Filho } \\
2004\end{array}$ \\
\hline 21 & Luminárias & FLS LUMI & 21.48 & 940.5 & 17.8 & 489.0 & Rodrigues et al. 2003 \\
\hline 22 & Monte Carmelo & FLS MCAR & 18.45 & 910 & 20.6 & 795.5 & Prado Júnior et al. 2012 \\
\hline 23 & Campo Florido & FLS PANG & 19.15 & 800 & 20.9 & 844.1 & Oliveira et al. 2014 \\
\hline 24 & Perdizes & FLS PERD & 21.6 & 1480 & 17.6 & 382.3 & Oliveira-Filho et al. 2004 \\
\hline 25 & Uberlândia & FLS PERE & 18.55 & 734 & 20.9 & 417.5 & Sá et al. 2012. \\
\hline 26 & Uberlândia & FLS SJOSÉ & 18.51 & 915 & 20.9 & 872.5 & Prado Júnior et al. 2011 \\
\hline 27 & Uberaba & FLS UBE & 19.4 & 790 & 20.6 & 24.7 & Dias Neto et al. 2009 \\
\hline 28 & Viçosa & FLS VI1 & 20.45 & 742 & 19.5 & 604.0 & Campos et al. 2006 \\
\hline 29 & Viçosa & FLS VI2 & 20.45 & 742 & 19.5 & 417.5 & Silva et al. 2004 \\
\hline
\end{tabular}

As variáveis significativas correlacionadas positivamente para o eixo 1 foram: temperatura média e distância horizontal do oceano, as que apresentaram correlação significativa negativa foram: altitude e latitude. $\mathrm{O}$ eixo 2, apresentou alta correlação positiva apenas para a variável altitude.

Com a CCA ficou evidente a separação de três grupos (Figura 3): 1. florestas estacionais mais próximas à costa brasileira, 2. florestas estacionais de interior e 3. cerrados, em função da forte correlação entre as variáveis significativas. Resultados similares também foram obtidos na análise de cluster de similaridade florística com uma separação entre os três tipos de fitofisionomias (Figura 2). Segundo Higuchi et al (2013) as relações de similaridade florística podem ser estabelecidas em função do clima. No presente estudo, a temperatura média apresentou maior relevância na separação dos grupos do que a pluviosidade. Como a temperatura teve relação com a distinção 
fitofisionômica, é possível presumir que mudanças fitofisionômicas devem ocorrer em função do aumento de temperatura ambiental, o que pode ser alvo de futuros estudos.

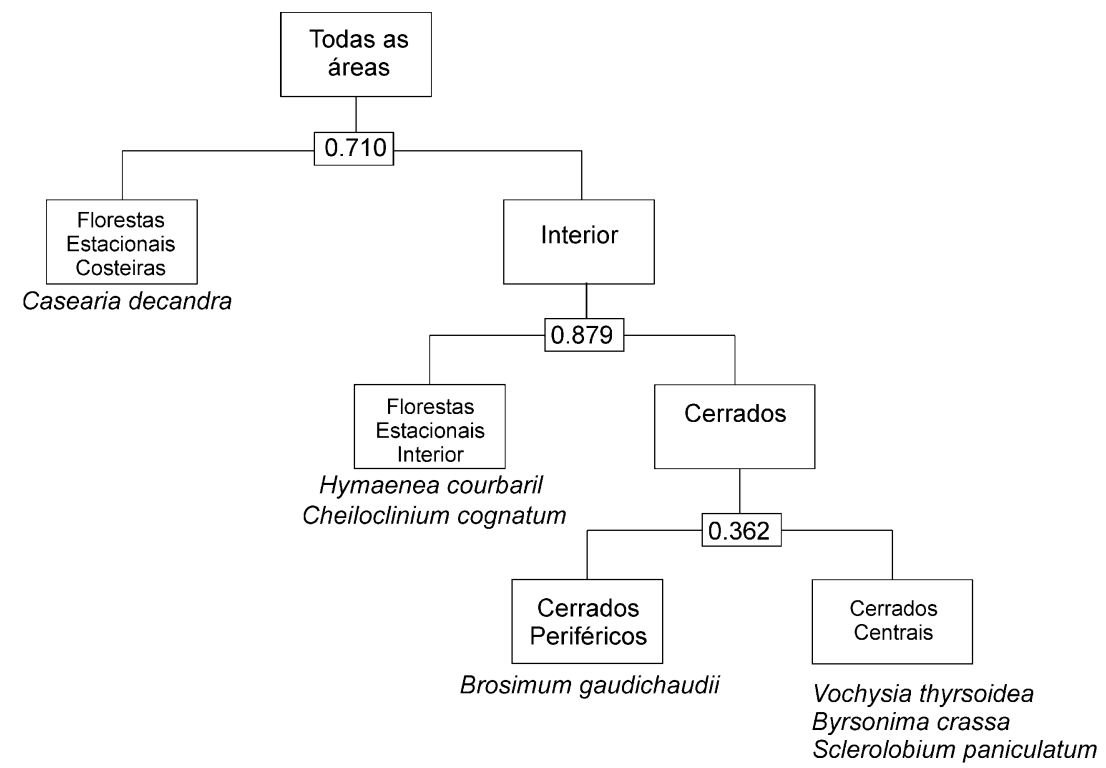

Figura 3. Análise do Twinspan para 34 áreas utilizando dados de densidade de espécies.

Em relação à pluviosidade, uma explicação provável para não ter sido um fator de separação fitofisionômica, pode ser o fato das áreas estarem sob clima sazonal e a pluviosidade não apresentar grande variação (mesmo quando separadas em estações do ano). Para os cerrados a média de pluviosidade por ano no período seco foi de $227 \mathrm{~mm}$ e no período chuvoso de $1284 \mathrm{~mm}$ com total de 1512 $\mathrm{mm}$ e para as florestas estes valores, respectivamente foram $220 \mathrm{~mm}, 1309 \mathrm{~mm}$ e $1531 \mathrm{~mm}$, logo não apresentando grandes variações.

É relevante citar que as utilizações de classificações climáticas são importantes para analisar agrupamentos de dados climáticos entre regiões. O sistema de Koppen é o mais visto e leva mais em consideração a pluviosidade e a temperatura, outra classificação alternativa e significativa é o uso da classificação climática de Holdridge, que utiliza de dados como latitude e altitude para associações ecológicas, o que pode ser importante para regiões do bioma Cerrado (Dias Cardoso et al. 2015; Mastella et al. 2019).

Além disso, não foram avaliados fatores importantes como o estágio de sucessão, tipo de solo, a proximidade de recursos hídricos e a ocorrência de incêndios, também responsáveis pela flora e estrutura de comunidades vegetais (Vale et al. 2015; Raymundo et al. 2018). Assim como na similaridade, as áreas de cerrado distantes do Brasil Central se aproximaram. Apenas as variáveis restantes parecem não ser suficientes para explicar tal proximidade e é possível que a melhor explicação esteja no solo e na distância entre essas áreas para as demais. Os solos são fundamentais para o estabelecimento de espécies vegetais em qualquer área e, especialmente os solos do Cerrado, pode ser entendido como um mosaico vegetacional, em que ocorrem diversos tipos de formações.

Áreas de cerrado com solos distróficos tendem a apresentar menores similaridades em relação com àquelas com maior fertilidade presentes no Brasil Central (Bueno et al 2013) e os solos de três cerrados agrupados no Cluster (CSS CGUI, CSSCUI, CSS RIO - Figura 2B), essas três áreas foram classificadas, pelos próprios autores, como solos bastante distróficos. O outro fator pode ser simplesmente a questão da distância, visto que essas foram as três áreas de cerrado mais distantes em relação as demais.

O grupo de áreas centralizado compreende uma região de transição de cerrado para floresta semidecidual condicionada aos fatores estudados. Oliveira-Filho e Fluminhan-Filho (1999) denominam a região como áreas de transição entre os cerrados do Brasil Central e as florestas semideciduais do sudeste do país.

No diagrama de ordenação (Figura 4) ficou visível a formação de grupos distintos, onde foi possível notar pelas variáveis altitude e latitude, que a posição geográfica foi importante para direcionar a ocorrência da formação de florestas semideciduais costeiras para as regiões mais elevadas do sudeste do país. Independente da formação (cerrados, florestas estacionais de interior, florestas estacionais costeiras), a altitude parece ter forte relação com a variação florística entre as áreas. O papel da variação altitudinal como condicionante da flora é mais fortemente verificado nas florestas estacionais costeiras, pois o relevo tem grande variação topográfica, mas também foi verificada para as 
florestas estacionais de interior e para cerrados. Logo, o papel da altitude deve ser mais bem estudado como determinante nas variações florísticas para áreas mais interioranas do Brasil.

A análise de correspondência canônica entre todas as áreas apresentou autovalores 0,8343 para o eixo 1 e 0,6552 para o eixo 2, representando $32,89 \%$ e $25,85 \%$ respectivamente, da variação dos dados. No diagrama de ordenação com todas as áreas
(Figura 4) ficou visível a formação de grupos distintos, onde foi possível notar que a posição geográfica (maior latitude e menor distância horizontal do oceano) foi importante para direcionar a ocorrência da formação de florestas semideciduais costeiras para as regiões mais elevadas do sudeste do país.

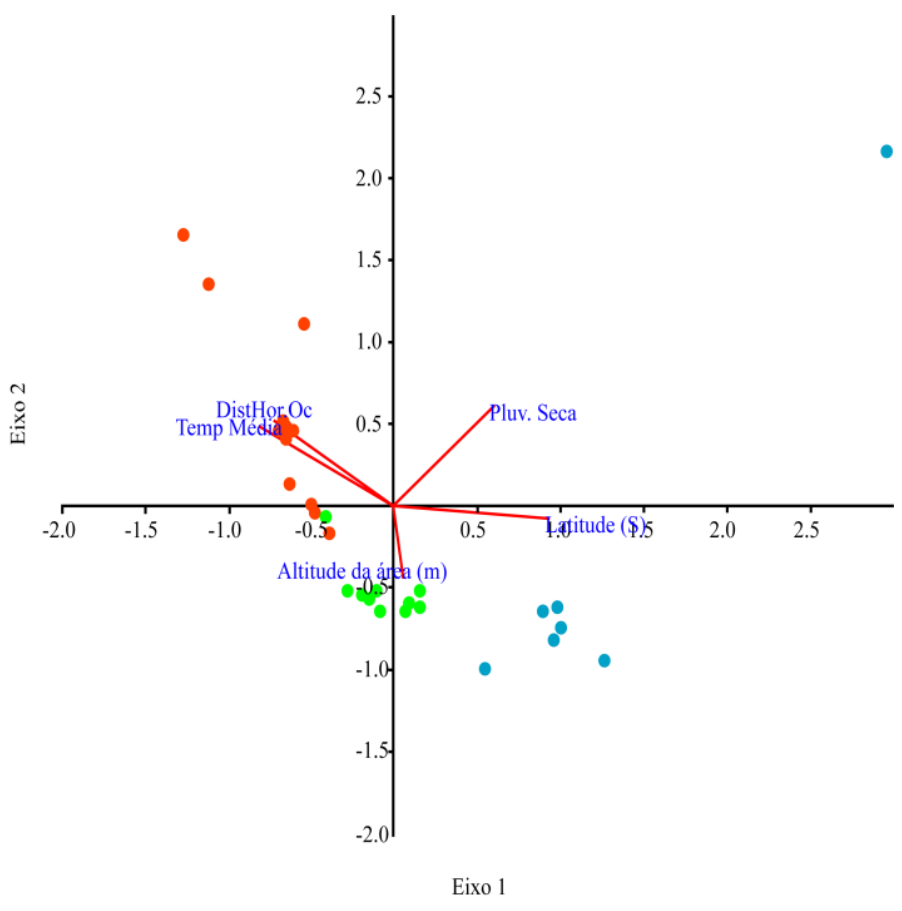

Figura 4. Análise de correspondência canônica para todas as áreas analisadas. As variáveis estão representadas por vetores e as áreas por círculos (as cores denotam as separações existentes dos dendrogramas onde azul = florestas estacionais semideciduais costeiras, verdes $=$ florestas estacionais semideciduais interioranas e laranja $=$ cerrados).

As áreas de cerrado apresentaram maior temperatura média enquanto que as florestas estacionais costeiras possuíram as maiores pluviosidades na estação seca. As semelhanças de temperatura nas áreas de Cerrado são influenciadas por suas proximidades geográficas (Silva et al, 2008). Ainda segundo Castro e Martins (1999), a temperatura média nas regiões de Cerrado seguem um padrão frequente de crescimento na direção sudeste-nordeste. Quanto aos valores de pluviosidade nas florestas costeiras, estes estão associados a presença dessas áreas em regiões sazonais, em que não ocorrem grandes variações pluviométricas.

Independente da formação (cerrados, florestas estacionais de interior, florestas estacionais costeiras), a altitude parece ter relativa relação com a variação florística entre as áreas. O papel da variação altitudinal como condicionante da flora é mais fortemente verificado nas florestas estacionais costeiras, pois o relevo tem grande variação topográfica, mas também foi verificada para as florestas estacionais de interior. Logo, o papel da altitude deve ser mais bem estudado como determinante nas variações florísticas para áreas mais interioranas do Brasil.

O grupo formado pelas florestas semideciduais de interior, apesar de apresentar características próprias, pode ser entendida como uma região de transição entre a fitofisionomia de cerrado e as florestas semideciduais costeiras, devido ao fato de sofrer influência das mesmas variáveis que afetam os dois grupos, latitude e temperatura, e por ser um intermediário geográfico. De acordo com Meireles et al (2014), o mosaico de vegetação que se forma no sul do estado de Minas Gerais é devido à combinação de dois fatores: a transição para os climas mais estacionais do Brasil Central e as altitudes elevadas próximo à costa.

O diagrama de ordenação para as áreas de cerrado (Figura 5) houve separação causada por maiores altitudes em cerrados localizados em Brasília e Caldas Novas, separação por maiores latitudes (Sete Lagoas e Três Marias) e separação 
causada pela pluviosidade na estação seca, temperatura média, longitude e distância horizontal do oceano para as áreas de Ribas do Rio, Chapada dos Guimarães e Cuiabá, localizadas na região mais a oeste dentre as áreas analisadas. Os autovalores foram de 0,5156 para o eixo 1 com variação de $28,9 \%$ e 0,4058 para o eixo 2 , variando $22,74 \%$.

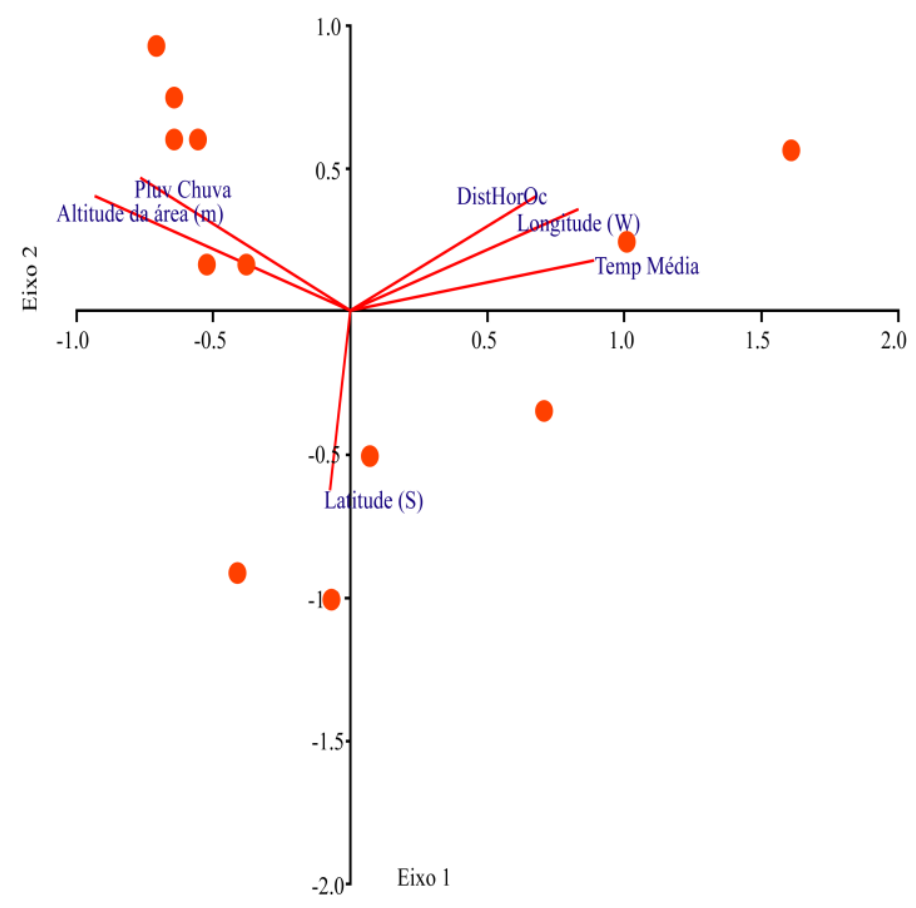

Figura 5. Análise de correspondência canônica (CCA) para as áreas de cerrado analisadas com as variáveis que mais corresponderam representada pelo vetor vermelho.

Castro e Martins (1999) caracterizaram uma divisão dos cerrados do Brasil em três partes, devido a barreiras climáticas e altitudinais: Cerrados do Sudeste Meridional, Cerrados do Planalto Central e Cerrados do Nordeste. Segundo os mesmos autores, a definição do padrão florístico nos Cerrados, de maneira geral, é lati-altitudinal. Entretanto, Ratter et al. (2003) dividiram o Cerrado em dois grandes grupos: áreas de savana amazônica (ao norte do Rio Amazonas) e áreas centrais do cerrado. Neste caso, as áreas centrais do cerrado correspondem as de maiores altitudes (entre 900 a $1200 \mathrm{~m}$ ) e latitude, classificadas pelos autores em um mesmo grupo de Cerrado. No presente estudo, nossos resultados evidenciaram separações das áreas de Cerrado em grupos distintos a partir das mesmas variáveis (latitude e altitude).

Para Ratter et al. (2003) e Ratter et al. (2011), os fatores edáficos são determinantes para formar a composição florística dos ambientes de Cerrado, sendo o tipo de solo (distrófico ou mesotrófico) o terceiro gradiente mais importante para determinação florística (atrás da latitude e longitude). Solos distróficos tendem a uma maior riqueza e densidade vegetacional, em relação aos solos mesotróficos (Rodrigues e Araújo, 2013).

No diagrama de ordenação para as áreas de floresta (Figura 6) obteve autovalores de 0,8844 e variação dados de 40,93\% no eixo 1 , já no eixo 2 foi de 0,8196 e 37,94\%. Foi apresentada clara distinção entre as florestas interioranas (maiores temperaturas médias e distancia horizontal do oceano) e florestas costeiras. Estas duas variáveis são consideradas importantes na separação de florestas atlânticas úmidas e estacionais (Oliveira-Filho e Fontes 2000). A maior pluviosidade na estação seca foi mais correlacionada do que a pluviosidade total na separação das áreas costeiras de maior latitude. Isto, porquê, em áreas de maior latitude, ocorrem maiores incidências de raios solares, possibilitando processos de evaporação em maiores velocidades e maiores frequências das chuvas. 


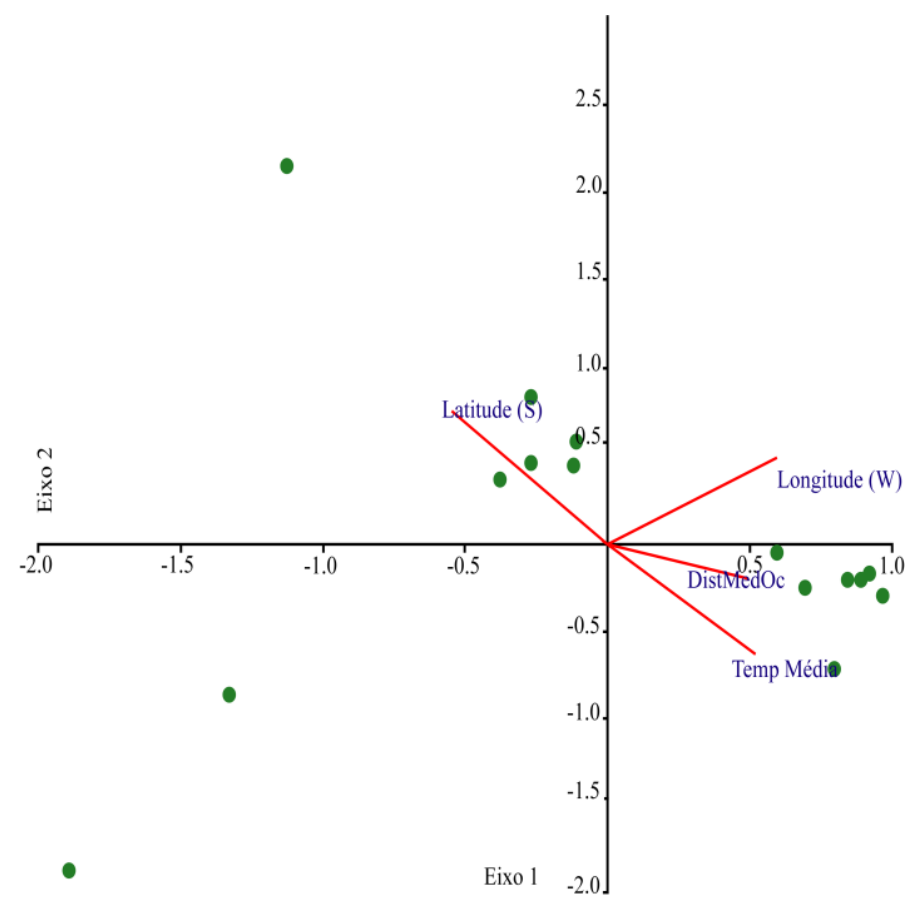

Figura 6. Análise de correspondência canônica (CCA) para as áreas de floresta analisadas com as variáveis de maior correspondência, essas, representadas em vetores vermelhos.

A altitude teve mais relação como componente diferenciador da flora ao longo das florestas costeiras, mas apresentaram pouca variação entre as florestas estacionais.
Espécies indicadoras dos grupos formados - A primeira divisão da classificação final pelo método Twinspan, cujo autovalor foi considerado alto $(0,710)$ formou dois grandes grupos (Figura 7 ).

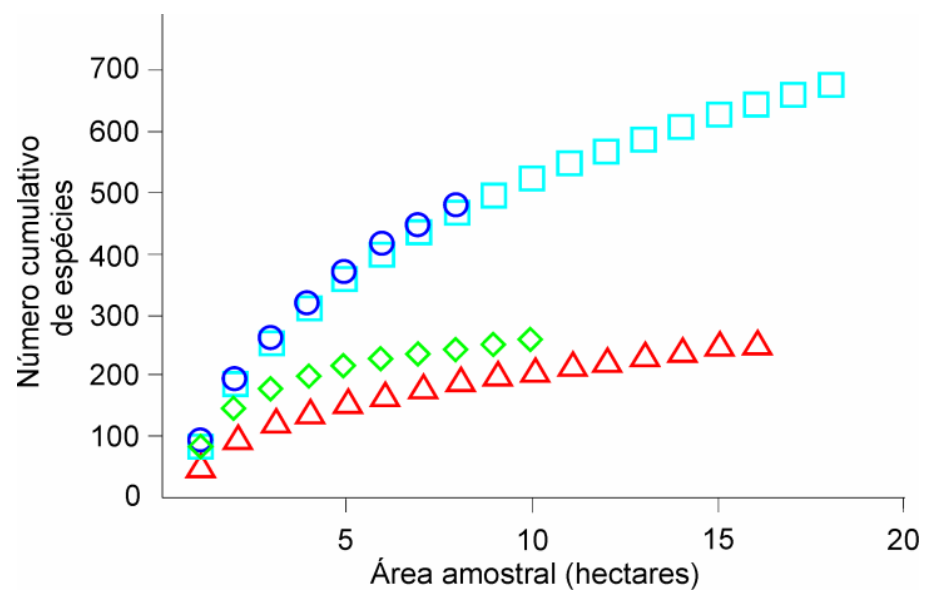

Figura 7. Curvas de rarefação realizados com estimador de riqueza Bootstrap para cerrados (triângulo), florestas estacionais interioranas (losango), florestas estacionais costeiras (círculo) e florestas no geral (quadrado).

O primeiro, formado pelas florestas estacionais mais próximas da zona costeira, cuja espécie indicadora foi Casearia decandra Jacq. e as florestas estacionais do interior e de cerrado (ou seja, uniu as áreas de interior em um grupo único). Este grupo ainda foi subdividido em florestas estacionais semideciduais de interior e áreas de cerrado stricto sensu, com autovalor de 0,879. As espécies indicadoras das florestas interioranas foram Hymaenea courbaril e Cheiloclinium cognatum. As áreas de cerrado ainda foram subdivididas em "cerrados localizados na zona periférica do domínio" cuja espécie indicadora foi Brosimum gaudichaudii Trécul e "cerrados localizados na região central do domínio" cujas espécies indicadoras foram Vochysia thyrsoidea Pohl., Byrsonima crassa Nied. e Sclerolobium paniculatum Vogel. A divisão é considerada representativa quando os autovalores estão próximos ou acima de 0,30 (Gauch, 1982), por esta razão, não realizamos mais subdivisões nesta análise.

Riqueza florística dos grupos formados - As curvas de rarefação demonstraram que tanto para cerrados quanto para florestas estacionais 
interioranas, a riqueza para cerca de 5-10 hectares fica em torno de 150-200 espécies, já para florestas costeiras, estes valores se aproximam de 500 espécies (Figura 6). As florestas como um todo têm padrão semelhante às florestas costeiras. Estas duas curvas de riqueza acumulada foram as que apresentaram menor tendência à estabilização. O grande número de espécies existentes nas florestas costeiras pelo fato de possuírem uma diferença altitudinal mais proeminente deve ser fator importante para a não estabilização da riqueza (Sinha et al. 2018). As áreas com maior $(1480 \mathrm{~m}) \mathrm{e}$ menor (372 m) altitude, são florestas costeiras, o que deve ter influenciado a grande diferenciação florística neste grupo.
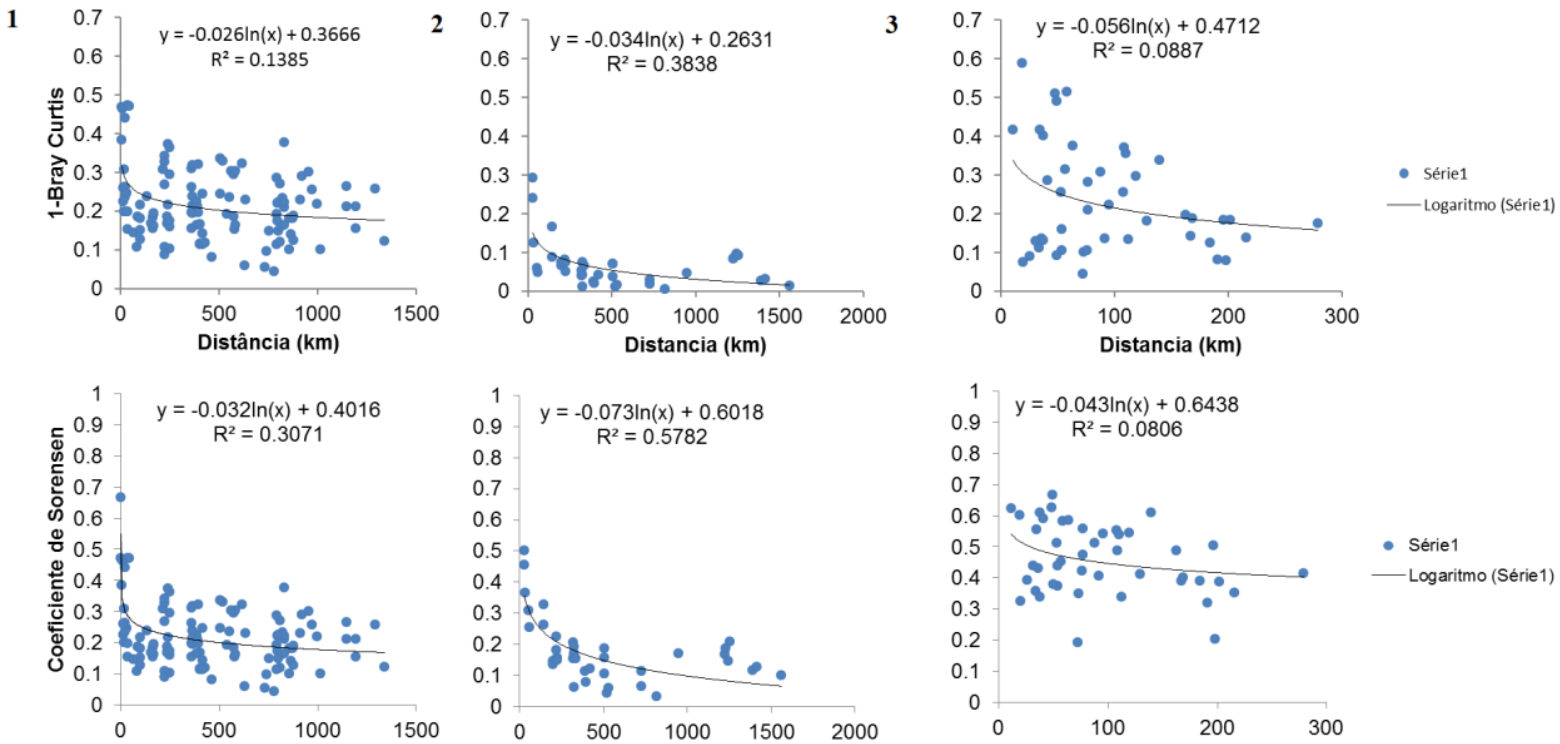

Figura 8. Regressões entre distância e coeficientes de similaridade para cerrados stricto sensu, florestas estacionais costeiras e florestas estacionais interioranas. Na parte de cima Bray Curtis e em baixo Coeficiente de Sørensen (1 = cerrados stricto sensu; 2 = florestas estacionais costeiras; 3 = florestas estacionais interioranas).

Efeito da distância- Mesmo as regressões entre distância e similaridade baseada no coeficiente de Sørensen serem fracas, foram significativas para o cerrado stricto sensu e florestas costeiras. Os valores dos coeficientes de determinação entre a distância e o coeficiente de similaridade Sørensen das florestas costeiras $\left(\mathrm{F}=8,9, \mathrm{p}<0.005, \mathrm{R}^{2}=0,57\right)$ foram superiores aos dos cerrados stricto sensu $(\mathrm{F}=$ $\left.10,9, \mathrm{p}<0,001, \mathrm{R}^{2}=0,31\right)$ e aos das florestas interioranas $\left(\mathrm{F}=4,54, \mathrm{p}<0,05, \mathrm{R}^{2}=0,08\right)$ (Figura 7). Os altos valores de $\mathrm{R}^{2}$ para as florestas costeiras e cerrados stricto sensu indicam que a distância tem papel importante na similaridade florística. Quanto maior é a distância geográfica entre duas áreas, maior é a tendência das áreas com mesma fitofisionomia apresentar menor similaridade. Contudo, para florestas costeiras e cerrados, este efeito não é necessariamente igual. $\mathrm{O}$ efeito do aumento da distância e o aumento da dissimilaridade florística é conhecido para florestas atlânticas (Neto et al., 2013), porém o tamanho deste efeito parece ser distinto para cada fitofisionomia. Para as florestas estacionais interioranas, por exemplo, o aumento da distância tende a reduzir a similaridade, porém menos do que as demais fitofisionomias. Assim florestas estacionais interioranas distantes podem possuir elevada similaridade e devem ser tratadas como uma fitofisionomia distinta das demais (DryFlor 2016).

As regressões entre distância e similaridade baseada no coeficiente de Bray-Curtis (baseado na densidade das espécies) também foram significativos. Os valores dos coeficientes de determinação entre a distância e o coeficiente de similaridade Bray-Curtis para as florestas costeiras $\left(\mathrm{F}=4,8, \mathrm{p}<0.05, \mathrm{R}^{2}=0,38\right)$ foram superiores aos cerrados stricto sensu $\left(\mathrm{F}=7,4, \mathrm{p}<0.01, \mathrm{R}^{2}=0,14\right)$ e às florestas interioranas $\left(\mathrm{F}=4,2, \mathrm{p}<0,05, \mathrm{R}^{2}=\right.$ 0,09) (Figura 7) Assim, o efeito sobre a mudança florística parece ser mais relevante do que mudanças acerca das espécies mais densas, sobretudo para os cerrados onde o coeficiente de determinação foi muito superior na análise florística em relação à estrutural. Isso deve significar que, nos cerrados, as espécies mudam ao longo da paisagem, mas muitas das principais permanecem as mesmas, o que minimiza o efeito da distância. Existe um grupo de espécies frequentemente amostradas em cerrados stricto sensu, independentemente da região de estudo e muitas vezes com elevada densidade, o que torna a similaridade de áreas distintas semelhante (Ratter et al., 2003; Bridgewater et al., 2004). Já florestas costeiras têm forte mudança de espécies e de espécies principais conforme a distância aumenta, 
logo as espécies dominantes da vegetação podem mudar mesmo a pequenas distancias.

\section{Conclusões}

A similaridade florística entre as duas fitofisionomias cerrado stricto sensu e floresta estacional semidecidual geraram padrões distintos. Enquanto o cerrado não demonstrou forte separação florística, as florestas estacionais puderam ser subdivididas, floristicamente, em floresta semidecidual de interior e floresta semidecidual costeira. As principais variáveis abióticas determinantes para as distinções florísticas foram temperatura, distância do oceano e latitude, indicando que a posição geográfica influencia diretamente na composição florística da formação vegetal. A distância entre as áreas de cerrado sentido restrito e floresta semidecidual costeiras tem papel mais relevante, como causador de diferenciações florísticas, do que para florestas semideciduais de interior.

Logo, para cerrados e florestas semideciduais costeiras quanto maiores as distâncias entre as áreas, maiores serão as diferenças florísticas entre si. Como implicação deste resultado, é necessário valorizar áreas distantes entre si, para se conservar o máximo de espécies na paisagem.

\section{Agradecimentos}

Os autores agradecem à Fundação de Amparo à Pesquisa do Estado de Goiás (FAPEG) e Coordenação de Aperfeiçoamento de Pessoal de Nível Superior (CAPES) pelas bolsas concedidas aos mestrandos, à UEG pela Bolsa de Incentivo à Pesquisa (BIP) concedida ao coordenador do projeto e pelo financiamento através do PróProjetos/Pesquisa (Edital 29/2016).

\section{Referências}

Assunção SL, Felfili JM (2004) Fitossociologia de um fragmento de cerrado sensu stricto na APA do Paranoá, DF, Brasil. Acta Botanica Brasilica, 18(4): 903-909. doi: 10.1590/S0102-33062004000400021. Disponível em: https://www.scielo.br/scielo.php?script=sci_arttext \&pid=S0102-33062004000400021

Balduino APC, Souza AL, Meira Neto JAA, Silva AF, Silva Júnior MC (2005) Fitossociologia e análise comparativa da composição florística do cerrado da flora de Paraopeba-MG. Revista Árvore, 29(1): 25-34. doi: 10.1590/S010067622005000100004. Disponível em: https://www.scielo.br/scielo.php?script=sci_arttext \&pid=S0100-67622005000100004

Barretto EHP, Catharino ELM (2015) Florestas maduras da região metropolitana de São Paulo: diversidade, composição arbórea e variação florística ao longo de um gradiente litoral-interior,
Estado de São Paulo, Brasil. Hoehnea, 42(3): $445-$ 469. doi:10.1590/2236-8906-72/2014. Disponível em: https://www.scielo.br/scielo.php?pid=S2236$89062015000300445 \&$ script $=$ sci_abstract $\&$ tlng $=$ pt

Braak CJF (1987) Analysis of vegetationenvironment relationships by canonical correspondence analysis. Vegetatio, 69(1-3): 69-77. doi: 10.1007/BF00038688. Disponível em: https://link.springer.com/article/10.1007/BF000386 88

Bridgewater S, Ratter J A, Ribeiro J F (2004) Biogeographic patterns, beta-diversity and dominance in the cerrado biome of Brazil. Biodiversity and Conservation, 13(12): 2295-2318. doi: $\quad$ 10.1023/B:BIOC.0000047903.37608.4c. Disponível

em: https://link.springer.com/article/10.1023/B:BIOC.0 000047903.37608.4c

Bueno ML, Neves DRM, Souza AF, Oliveira Junior E, Damasceno Junior GA, Pontara V, Laura VA, Ratter JA (2013) Influence of edaphic factors on the floristic composition of an area of cerradão in the Brazilian central-west. Acta Botanica Brasilica, 27(2): 445-455. doi: 10.1590/S0102$33062013000200017 . \quad$ Disponível em: https://www.scielo.br/scielo.php?script=sci_arttext \&pid=S0102-33062013000200017

Campos EP, Silva AF, Meira Neto JAA, Martins SV. Florística e estrutura horizontal da vegetação arbórea de uma ravina em um fragmento florestal no município de Viçosa, MG. Revista Árvore, 30(6): 1045-1054. doi: 10.1590/S010067622006000600021. Disponível em: https://www.scielo.br/scielo.php?pid=S0100$67622006000600021 \&$ script $=$ sci_abstract\&tlng=pt

Carielo P, Ferreira RA, Fior PM, Giuli JW, Reis M (2012) Levantamentos florístico e fitossociologístico de um trecho de cerrado da Fazenda Boa Aguada, município de Ribas do Rio Pardo - MS. Colloquium Agrariae, 8(1): 63-70. Disponível em https://scholar.google.com/scholar_lookup?title=Le vantamentos+flor\%C3\% ADstico+e+fitossociol\%C $3 \%$ B3 gico+de+um+trecho+de+cerrado+da+Fazend a+Boa+Aguada, + munic $\%$ C3\%ADpio+de+Ribas $+d$ o+Rio+Pardo+-

+ MS\&author=CARIELO+P.\&publication_year=20 $12 \&$ journal $=$ Colloquium + Agrariae $\&$ volume $=8 \&$ iss $\mathrm{ue}=$ nesp $\&$ pages $=63-70$

Castro AAJF, Martins FR (1999) Cerrados do Brasil e do Nordeste: Caracterização, área de ocupação e considerações sobre a sua fitodiversidade. Pesquisa em Foco, 7(9): 1-23. CDU 581.9(81:812/813) 
Chaves ADCG, Santos RMS, Santos JO, Fernandes AA, Maracajá PB (2013) A importância dos levantamentos florísticos e fitossociológico para a conservação e preservação das florestas. Agropecuária Científica no Semi-Árido, 9(2): 42-48. doi: 10.30969/acsa.v9i2.449. Disponível em: http://revistas.ufcg.edu.br/acsa/index.php/ACSA/art icle/view/449

Colwell, RK (2005) EstimateS: Statistical estimation of species richness and shared species form samples. Versão 7.5 Connecticut, EUA. Disponível em: https://www.researchgate.net/publication/24764276 0_Statistical_Estimation_of_Species_Richness_and _Shared_Species_from_Samples

Colwell RK, Coddington JA (1994) Estimating terrestrial biodiversity through extrapolation. Philosophical Transactions of the Royal Society, 345 (1311): 101-118. doi: 10.1098/rstb.1994.0091.

Dias Cardoso MR, Marcuzzo FFN, Barros JR, (2012) Caracterização da temperatura do ar no estado de Goiás e no Distrito Federal. Revista Brasileira de Climatologia, 8: 119-134. doi: https://doi.org/10.5216/revgeoamb.v0i30.52906

Dias Neto OC, Schiavini I, Lopes SF, Vale VS, Gusson AE, Oliveira AP (2009) Estrutura fitossociológica e grupos ecológicos em fragmentos de Floresta Estacional Semidecidual, Uberaba, Minas Gerais, Brasil. Rodriguésia, 60(4):1087$1100 . \quad$ Disponível em: https://www.scielo.br/pdf/rod/v60n4/2175-7860rod-60-04-1087.pdf

Dice LR (1945) Measures of the amount of ecological association between species. Ecology, 26(3):297-307. doi: 10.2307/1932409. Disponível em:

https://esajournals.onlinelibrary.wiley.com/doi/10.2 307/1932409

DryFlor KB-R, Delgado-Salinas A, Dexter KG, Linares-Palomino R, Oliveira-Filho A, Prado D, Pullan M, Quintana C, Riina R, Rodríguez GM, Weintritt J, Aymard P, Castaño A, Ceballos-Mago N, Cogollo Á, Cuadros H, Delgado F, Galetti WLA, Gonto R, González R, Graveson R, Helmer EH, Idárraga Á, Melo R, Mijares F, Mogni V, Molina D, Moreno NP, Nassar JM, Ríos DMME, Rivera O, Rodríguez N, Rojas A, Särkinen T, Sánchez R, Smith M, Vargas C, Villanueva B, Pennington RT (2016) Plant diversity patterns in neotropical dry forests and their conservation implications. Science. 353(6306): 1383-1387. doi: 10.1126/science.aaf5080. Disponível em: https://science.sciencemag.org/content/353/6306/13 83
Espírito-Santo FDB, Oliveira-Filho AT, Machado ELM, Souza JS, Fontes MAL, Marques JJGSM (2002) Variáveis ambientais e a distribuição de espécies arbóreas em um remanescente de Floresta Estacional Semidecidual Montana no Campus da Universidade Federal de Lavras, MG. Acta Botanica Brasilica, 16(3): 331-356. doi: 10.1590/S0102$33062002000300006 . \quad$ Disponível em: https://www.scielo.br/scielo.php?pid=S010233062002000300006\&script=sci_abstract\&tlng=pt

Farias RAvB, Barbosa ACC, Ferreira MFM, Ventura MJS, Pádua JAR (2012) Correlação espécie-ambiente em descrição e análise da vegetação. Enciclopédia Biosfera, 8(15): 528-550. Disponível

em: http://www.conhecer.org.br/enciclop/2012b/ciencia s\%20agrarias/correlacao\%20especie.pdf

Felfili JM, Roitman I, Medeiros MM, Sanchez M (2011) Procedimentos e métodos de amostragem de vegetação. In: Felfili, JM, Eisenlhor PV, Melo MMRF, Andrade LA, Meira-Neto JAA (ed) Fitossociologia no Brasil - Métodos e estudo de casos. Viçosa: Universidade Federal de Viçosa. p. 86-121.

Flora do Brasil 2020 em construção. Jardim Botânico do Rio de Janeiro. Disponível em: < http://floradobrasil.jbrj.gov.br/ >. Acesso em: 09 abril. 2020

Fonseca MS, Silva Junior MC (2004) Fitossociologia e similaridade florística entre trechos de cerrado sentido restrito em interflúvio e em vale no Jardim Botânico de Brasília, DF. Acta Botanica Brasílica, 18(1): 19-29. doi: 10.1590/S0102$33062004000100003 . \quad$ Disponível em: https://www.scielo.br/pdf/abb/v18n1/v18n1a03.pdf

Gauch, H. G. J (1982) Multivariate analysis in community ecology. $1^{\mathrm{a}}$ edição. Cambridge: Cambridge University Press. 312 p. Disponível em: https://www.researchgate.net/publication/26840429 3_Multivariate_Analysis_of_Ecological_Communit ies.

Giácomo RG, Carvalho DC, Pereira MG, Souza AB, Gaui TD (2013) Florística e fitossociologia em áreas de campo sujo e cerrado sensu stricto na estação ecológica de Pirapitinga-MG. Ciência Florestal, 23(1):29-43. doi: 10.5902/198050988437. Disponível em: https://www.scielo.br/pdf/cflo/v23n1/1980-5098cflo-23-01-00029.pdf

Google. Google Earth. Version 7.1.8.3036 (32-bit). $2017 . \quad$ Disponível em: <https://www.google.com.br/earth/download/ge/agr ee.html>. Acesso em: 14/06/2017. 
Gusson AE, Lopes SF, Dias Neto OC, Vale VS (2009) Características químicas do solo e estrutura de um fragmento de Floresta Estacional Semidecidual em Ipiaçu, Minas Gerais, Brasil. Rodriguésia, 60(2): 403-414. doi:10.1590/2175$7860200960212 . \quad$ Disponível em: https://www.scielo.br/pdf/rod/v60n2/2175-7860rod-60-02-0403.pdf

Hammer, Ø (2001) PAST: Paleontological Statistics Software Package for Education and Data Analysis. Versão 3.20. Oslo, Noruega.

Higuchi P, Silva AC, Budke JC, Mantovani A, Bortoluzzi RLC, Ziger AA (2013) Influência do clima e de rotas migratórias de espécies arbóreas sobre o padrão fitogeográfico de florestas na região sul do Brasil. Ciência Florestal, 23(4): 539-553. doi: 10.5902/1980509812338. Disponível em: https://www.scielo.br/pdf/cflo/v23n4/1980-5098cflo-23-04-00539.pdf

Higuchi, P, Silva AC, Ferreira TS, Souza ST, Gomes JP, Silva KM, Paulino PS (2012) Influência de variáveis ambientais sobre o padrão estrutural e florístico do componente arbóreo, em um fragmento de Floresta Ombrófila Mista Montana em Lages, SC. Ciência Florestal, 22(1): 79-90. doi: 10.5902/198050985081. Disponível em: https://www.scielo.br/pdf/cflo/v22n1/1980-5098cflo-22-01-00079.pdf

Hill MO (1979) Twinspan: a FORTRAN Programme for arranging multivariate data in an ordered two way table by classification of the individuals and the attributes. $1^{\mathrm{a}}$ edição. Nova Iorque: Cornell University. 49 p. Disponível em: https://www.researchgate.net/publication/24031131 0_TWINSPAN-

A_Fortran_Program_for_Arranging_Multivariate_ Data_in_an_Ordered_Two-

way_Table_by_Classification_of_The_Individuals_ and_Attributes

Horn, HS (1996) Measurement of "overlap" in comparative ecological studies. The American Naturalist, 100(914): 419-424. Disponível em: https://www.jstor.org/stable/2459242

\footnotetext{
INSTITUTO BRASILEIRO DE GEOGRAFIA ESTATÍSTICA - IBGE (2012) Sistemas fitogeográfico. In: Manual técnico da vegetação brasileira: Sistema fitogeográfico, inventário das formações florestais e campestres, técnicas e manejo de coleções botânicas, procedimentos para mapeamentos. Rio de Janeiro: IBGE. p 16-164. Disponível em: https://uc.socioambiental.org/sites/uc/files/201912/liv63011.pdf
}

Kilca RV, Schiavini I, Araújo GM, Fagg JMF (2009) Diferenças edáficas e estruturais entre duas florestas estacionais no bioma Cerrado. Neotropical Biology and Conservation, 4(3): 150-163. doi: 10.4013/nbc.2009.43.05. Disponível em: https://www.researchgate.net/publication/43692946 _Diferencas_edaficas_e_estruturais_entre_duas_flo restas_estacionais_no_bioma_Cerrado

Kilca RV, Schiavini I, Monteiro GA (2014) Padrões florísticos em dois tipos de Florestas Estacionais no Cerrado. Bioscience Journal, 30(3): 903-913. Disponível

em: http://www.seer.ufu.br/index.php/biosciencejournal /article/view/19585

Kratka PC, Ataídes RP (2015) Caracterização da vegetação arbórea-arbustiva da Reserva Biológica do Guará, DF, para elaboração do plano de manejo desta unidade de conservação. Heringeriana, 8(1): 53-80. Disponível em: http://revistas.jardimbotanico.ibict.br/index.php/her ingeriana/article/view/96/91

Krebs CJ, 1989. Ecological metodology. Harper Collins Publishers, New York, EUA.

Lima RAF, Rando JG, Barreto KD (2014) Composição e diversidade no Cerrado do leste de Mato Grosso do Sul, Brasil. Revista Árvore, 39(1): 9-24. doi:10.1590/0100-67622015000100002. Disponível em: https://www.scielo.br/pdf/rarv/v39n1/0100-6762rarv-39-01-0009.pdf

Lopes SF, Schiavini I, Oliveira AP, Vale VS (2011c) An ecological comparison of floristic composition in seasonal semideciduous forest in southeast Brazil: implications for conservation. International Journal of Forestry Research, 2012(1): 1-14. doi: 10.1155/2012/537269. Disponível em: http://downloads.hindawi.com/journals/ijfr/2012/53 7269.pdf

Lopes SF, Schiavini I, Prado Júnior, JA, Gusson AE, Souza Neto AR, Vale VS, Dias Neto OC (2011b) Caracterização ecológica e distribuição diamétrica da vegetação arbórea em um remanescente de floresta estacional semidecidual, na Fazenda Experimental do Glória, Uberlândia, MG. Bioscience Journal, 27(2): 322-335. Disponível em: http://www.seer.ufu.br/index.php/biosciencejournal /article/view/8176

Lopes SF, Vale VS, Schiavini I (2009) Efeito de queimadas sobre a estrutura e composição da comunidade vegetal lenhosa do cerrado sentido restrito em Caldas Novas, GO. Revista Árvore, 33(4): 695-704. doi: 10.1590/S0100- 
67622009000400012. Disponível em: https://www.scielo.br/pdf/rarv/v33n4/v33n4a12.pdf

Lopes SF, Vale VS, Oliveira AP, Schiavini I (2011a) Análise comparativa da estrutura e composição florística de Cerrado no Brasil Central. Interciencia, 36 (1): 8-15. Disponível em: https://www.interciencia.net/wpcontent/uploads/2018/01/008-LOPES-8.pdf

Lopes WP, Silva AF, Souza AL, Meira Neto JAA (2002) Estrutura fitossociológica de um trecho de vegetação arbórea no Parque Estadual do Rio Doce Minas Gerais, Brasil. Acta Botanica Brasílica, 16(4): $\quad 443-456 . \quad$ doi: $10.1590 /$ S0102$33062002000400007 . \quad$ Disponível em: https://www.scielo.br/pdf/abb/v16n4/a07v16n4.pdf

Machado ELM, Oliveira-Filho AT (2002) Spatial patterns of tree community dynamics are detectable in a small (4 ha) and disturbed fragment of the Brazilian Atlantic Forest. Acta Botanica Brasilica, 24(1): 250-261. doi: 10.1590/S0102$33062010000100027 . \quad$ Disponível em: https://www.scielo.br/pdf/abb/v24n1/27.pdf

Mastella ADF, Ivasko Júnior S, Tres A, Tetto AF, Wendling WT, Soares RV (2019) Classificação do estado de Goiás e do Distrito Federal segundo o sistema de zonas de vida de holdridge. Revista Brasileira de Geografia Física, 12(02): 443-456. doi: 10.26848/rbgf.v12.2.p443-456

Meireles LD, Kinoshita LS, Shepherd GJ (2014) Composição florística da vegetação altimontana do distrito de Monte Verde (Camanducaia, MG), Serra da Mantiqueira Meriodinal, Sudeste do Brasil. Rodriguésia, 65(4): 831-859. doi: 10.1590/2175$7860201465403 . \quad$ Disponível em: https://www.scielo.br/pdf/rod/v65n4/a03v65n4.pdf

McCune B, Mefford MJ (2011). PC-ORD. Multivariate Analysis of Ecological Data. Versão 6.0. Oregon, EUA.

Neto JLR, Lopes UGC, Moura FBP (2013) Effects of soil, altitude, rainfall, and distance on the floristic similarity of Atlantic Forest fragments in the eastNortheast. Biotemas, 26(3): 91-98. doi: 10.5007/2175-7925.2013v26n3p91. Disponível em: https://periodicos.ufsc.br/index.php/biotemas/article /view/2175-7925.2013v26n3p91/25303

Nettesheim FC, Carvalho DC, Fonseca CC, Nunes RS, Cavalcanti DM, Gabriel MM, Menezes LFT (2010) Estrutura e florística do estrato arbóreo no cerrado sensu stricto de Buritis, Minas Gerais, Brasil. Rodriguésia, 61(4): 731-747. doi: 10.1590/2175-7860201061413. Disponível em: https://www.scielo.br/pdf/rod/v61n4/2175-7860rod-61-04-0731.pdf

Neves DM, Dexter KG, Pennington RT, Valente AS M, Bueno ML, Eisenlohr PV, Fontes MAL, Miranda PLS, Moreira SN, Rezende VL, Saiter FZ, OliveiraFilho AT (2017) Dissecting a biodiversity hotspot: The importance of environmentally marginal habitats in the Atlantic Forest Domain of South America. Diversity and Distributions, 23(1):898909. doi: 10.1111/ddi.12581. Disponível em: https://onlinelibrary.wiley.com/doi/epdf/10.1111/dd i. 12581

Oliveira AP, Schiavini I, Vale VS, Lopes SF, Arantes CS, Gusson AE, Prado Júnior JA, Dias Neto OC (2014) Mortality, recruitment and growth of the tree communities in three forest formations at the Panga Ecological Station over ten years (19972007). Acta Botanica Brasilica, 28(2): 234-248. doi: 10.1590/S0102-33062014000200010. Disponível em:

https://www.scielo.br/pdf/abb/v28n2/a10v28n2.pdf

Oliveira-Filho AT, Carvalho DA, Fontes MAL, Berg EVD, Curi N, Carvalho WAC (2004) Variações estruturais do compartimento arbóreo de uma floresta semidecídua alto-montana na Chapada das Perdizes, Carrancas, MG. Brazilian Journal of Botany, 27(2): 291-309. doi: 10.1590/S010084042004000200009. Disponível em: https://www.scielo.br/pdf/rbb/v27n2/v27n2a09.pdf

Oliveira-Filho, A. T.; Fluminhan-Filho, M (1999) Ecologia da vegetação do Parque Florestal quedas do Rio Bonito. Cerne, 5(2): 51-64. Disponível em: http://www.bibliotecaflorestal.ufv.br/bitstream/han dle/123456789/18282/Cerne_v5_n2_p5164_1999.pdf?sequence $=1 \&$ isAllowed $=y$

Oestreich Filho E (2014) Fitossociologia, diversidade e similaridade entre fragmentos de cerrado stricto sensu sobre neossolos quartzarênicos órticos, nos municípios de Cuiabá e Chapada dos Guimarães, estado de Mato Grosso, Brasil. Dissertação, Faculdade de Engenharia Florestal, Universidade Federal do Mato Grosso. 88p. Disponível em: https://www1.ufmt.br/ufmt/unidade/userfiles/public acoes/4cee2f0125b1aaeca9dd563566dd2ddc.pdf

Prado Júnior JA, Lopes SF, Schiavini I, Vale VS, Oliveira AP, Gusson AE, Dias Neto OC, Stein M (2012) Fitossociologia, caracterização sucessional e síndromes de dispersão da comunidade arbórea de remanescente urbano de Floresta Estacional Semidecidual em Monte Carmelo, Minas Gerais. Rodriguésia, 63(3): 459-499. doi: 10.1590/S2175$78602012000300001 . \quad$ Disponível em: https://www.scielo.br/pdf/rod/v63n3/a01v63n3.pdf 
Prado Júnior JA, Lopes SF, Vale VS, Oliveira AP (2011) Estrutura e caracterização sucessional da comunidade arbórea de um remanescente de Floresta Estacional Semidecidual, Uberlândia, MG. Caminhos de Geografia, 12(39): 81-93. Disponível em:

http://www.seer.ufu.br/index.php/caminhosdegeogr afia/article/view/16329

Prado Júnior JA, Vale VS, Oliveira AP, Gusson AE, Dias Neto OC, Lopes SF, Schiavini I (2010) Estrutura da comunidade arbórea em um fragmento de Floresta Estacional Semidecidual localizada na Reserva Legal da Fazenda Irara, Uberlândia, MG. Bioscience Journal, 26(4): 638-647. Disponível em: http://www.seer.ufu.br/index.php/biosciencejournal /article/view/7230/5141

Pereira BAS, Venturoli F, Carvalho FA (2011) Florestas estacionais no Cerrado: uma visão geral. Pesquisa Agropecuária Tropical, 41(3): 446-455. doi: 10.5216/pat.v41i3.12666. Disponível em: https://www.scielo.br/pdf/pat/v41n3/a19v41n3.pdf

Pereira IM, Oliveira NF, Gonzaga APD, Oliveira MLR, Machado ELM, Karam D (2013) Estrutura fitossociológica de uma área de cerrado sensu stricto em Sete Lagoas, MG. Enciclopédia Biosfera, 9(17): 3433-3446. Disponível em: https://ainfo.cnptia.embrapa.br/digital/bitstream/ite m/93601/1/Estrutura-fitossociologica.pdf

Peel MC, Finlayson BL, McMahon TA (2007) Updated world map of the Köppen-Geiger climate classification. Hydrological Earth Systems Science, 11 (5): 1633-1644. doi: 10.5194/hess-11-1633-2007. Disponível em: https://www.hydrol-earth-systsci.net/11/1633/2007/hess-11-1633-2007.pdf

Ratter JA, Bridgewater S, Ribeiro JF (2003) Analysis of the floristic composition of the brazilian cerrado vegetation III: comparison of the woody vegetation of 376 areas. Edinburgh of Botany, 60(1): 57-109. doi: 10.1017/S0960428603000064.

Ratter JA, Bridgewater S, Ribeiro JF, Fonseca-Filho J, Rodrigues SM, Milliken W, Pott A, Oliveira-Filho AT, Durigan G, Pennington RT (2011) Analysis of the floristic composition of the Brazilian Cerrado vegetation IV: revision of the comparison of the woody vegetation of 367 areas and presentation of a revised data-base of 367 areas. 1-85. http: //cerrado.rbge.org.uk/cerrado/download/download.p hp.

Raymundo D, Prado Júnior JA, Carvalho FA, Vale VS, Oliveira PE, Sande MTVS (2018) Shifting species and functional diversity due to abrupt changes in water availability in tropical dry forests. Journal of Ecology, 2019(107):1-12. doi:
10.1111/1365-2745.13031. Disponível em: https://besjournals.onlinelibrary.wiley.com/doi/epdf /10.1111/1365-2745.13031

Rodrigues RF, Monteiro AG (2013) Estrutura da vegetação e características edáficas de um cerradão em solo distrófico e em solo mesotrófico no Triângulo Mineiro. Bioscience Journal, 29(6). Disponível em: http://www.seer.ufu.br/index.php/biosciencejournal /article/view/22090

Rodrigues LA, Carvalho DA, Oliveira Filho AR, Botrel RT, Silva EA (2003) Florística e estrutura da comunidade arbórea de um fragmento florestal em Luminárias, MG. Acta Botanica Brasilica, 17(1): 71-87. doi: 10.1590/S0102-33062003000100006. Disponível em: https://www.scielo.br/pdf/abb/v17n1/a06v17n1.pdf Rodrigues-Souza J, Prado Júnior JA, Vale VS, Schiavini I, Oliveira AP, Arantes CS (2015) Secondary forest expansion over a savanna domain at an ecological reserve in the Southeastern Brazil after 15 years of monitoring. Brazilian Journal of Botany, 38(2):311-312. doi: 10.1007/s40415-0150146-x.

Roquette JG (2018) Ciência Florestal, 28(3): 13501363. doi: 10.5902/1980509833354.

Disponível em: https://www.scielo.br/pdf/cflo/v28n3/1980-5098cflo-28-03-1350.pdf

Sá D, Lopes SF, Prado Júnior JA, Schiavini I, Vale VS, Oliveira AP, Dias Neto OC, Gusson AE (2012) Estrutura e grupos ecológicos de um fragmento de Floresta Estacional Semidecidual no Triângulo Mineiro, Brasil. Caminhos de Geografia, 13(44): 89101. Disponível em: http://www.seer.ufu.br/index.php/caminhosdegeogr afia/article/view/17767

Scipioni MC, Longhi SJ, Brandelero C, Pedron FDA, Reinert DJ (2012) Análise fitossociológica de um fragmento de floresta estacional em uma catena de solos no morro do cerrito, Santa Maria, RS. Ciência Florestal, 22(3): 457-466. doi: 10.5902/198050986614. Disponível em: https://revistas.ufpr.br/floresta/article/view/17102/1 1263

Silva FAM, Assad ED, Steinke ET, Muller AG (2008) Clima do Bioma Cerrado. In: Albuquerque ACS, Silva AG (1 ed) Agricultura tropical : quatro décadas de inovações tecnológicas, institucionais e políticas. Rio Branco: Embrapa Acre. p. 93-144.

Silva NRS, Martins SV, Meira Neto JAA, Souza AL (2004) Composição florística e estrutura de uma floresta estacional semidecidual montana em Viçosa, 
MG. Revista Árvore, 28(3): 397-405. doi: 10.1590/S0100-67622004000300011. Disponível em:

https://www.scielo.br/pdf/rarv/v28n3/21607.pdf

Sinha S, Badola E K, Chhetri B, Gaira K S, Lepcha J, Dhyani P P (2018) Effect of altitude and climate in shaping the forest compositions of Singalila National Park in Khangchendzonga Landscape, Eastern Himalaya, India. Journal of Asia-Pacific Biodiversity, 11(2): 267-275. doi: 10.1016/j.japb.2018.01.012. Disponível em: https://www.sciencedirect.com/science/article/pii/S 2287884X18300554

Souza,JS, Espírito-Santo FDB, Fontes MAL, Oliveira-Filho ATD, Botezelli L (2003) Análise das variações florísticas e estruturais da comunidade arbórea de um fragmento de floresta semidecídua às margens do rio Capivari, Lavras-MG. Revista Árvore, 27(2): 185-206 doi: 10.1590/S010067622003000200009. Disponível em: https://www.scielo.br/pdf/rarv/v27n2/15938.pdf

Vale VS, Schiavini I, Lopes SF, Dias Neto OC, Oliveira AP, Gusson AE (2009) Composição florística e estrutura do componente arbóreo em um remanescente primário de floresta estacional semidecidual em Araguari, Minas Gerais, Brasil. Hoehnea, 36(3): 417-429. doi: 10.1590/S223689062009000300003. Disponível em: https://www.scielo.br/pdf/hoehnea/v36n3/v36n3a03 .pdf

Vale, VS, Schiavini I, Prado Júnior JA, Oliveira AP, Gusson AE (2015) Rapid changes in tree composition and biodiversity: consequences of dams on dry seasonal forests. Revista Chilena de Historia Natural (Impresa), 88(13): 1-11. doi: 10.1186/s40693-015-0043-5. Disponível em: https://revchilhistnat.biomedcentral.com/articles/10. 1186/s40693-015-0043-5

Vale VS, Araújo GM, Oliveira AS, Prado Júnior JA, Santos LCS (2017) Estrutura da comunidade arbórea e características edáficas de um fragmento urbano. Ciência Florestal, 27(4): 1415-1428. doi: 10.5902/1980509830322. Disponível em: https://periodicos.ufsm.br/cienciaflorestal/article/vi ew/30322/16800 